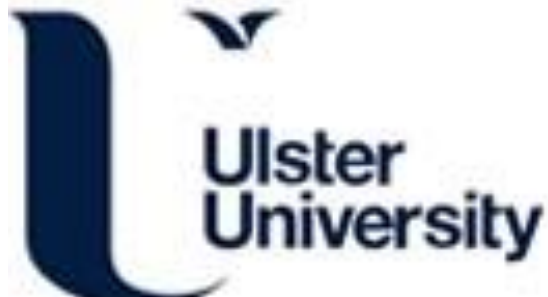

\section{A Combination of Curcumin from Turmeric and Alpha-linolenic Acid Shows Antagonism with MCF-7 Breast Cancer Cells in Phenol-red Free Medium}

Aldhirgham, T., Henderson, K., Nigam, P., \& Owusu-Apenten, R. K. (2016). A Combination of Curcumin from Turmeric and Alpha-linolenic Acid Shows Antagonism with MCF-7 Breast Cancer Cells in Phenol-red Free Medium. Journal of Applied Life Sciences International, 10(1), 1-12. https://doi.org/10.9734/JALSI/2017/29740

Link to publication record in Ulster University Research Portal

Published in:

Journal of Applied Life Sciences International

Publication Status:

Published (in print/issue): 22/12/2016

DOI:

10.9734/JALSI/2017/29740

Document Version

Publisher's PDF, also known as Version of record

\section{General rights}

Copyright for the publications made accessible via Ulster University's Research Portal is retained by the author(s) and / or other copyright owners and it is a condition of accessing these publications that users recognise and abide by the legal requirements associated with these rights.

\section{Take down policy}

The Research Portal is Ulster University's institutional repository that provides access to Ulster's research outputs. Every effort has been made to ensure that content in the Research Portal does not infringe any person's rights, or applicable UK laws. If you discover content in the Research Portal that you believe breaches copyright or violates any law, please contact pure-support@ulster.ac.uk. 


\title{
A Combination of Curcumin from Turmeric and Alpha-linolenic Acid Shows Antagonism with MCF-7 Breast Cancer Cells in Phenol-red Free Medium
}

\author{
Tahrir Aldhirgham ${ }^{1}$, Kathleen Henderson ${ }^{1}$, Poonam S. Nigam ${ }^{1}$ \\ and Richard Owusu-Apenten ${ }^{1^{*}}$ \\ ${ }^{1}$ Faculty of Life and Health Sciences, School of Biomedical Sciences, Ulster University, \\ Cromore Road, Coleraine, BT52 1SA, UK.
}

Authors' contributions

This work was carried out in collaboration between all authors. Authors ROA and PSN designed the study. Author ROA wrote the protocols. Authors TA and KH performed the experimental work, managed literature searches, performed data and statistical analyses. Author TA wrote the first draft of the manuscript. All authors read and approved the final manuscript.

Article Information

DOI: 10.9734/JALSI/2017/29740 Editor(s):

\section{ABSTRACT}

Aims: To determine the total phenols content and antioxidant capacity for turmeric and curcumin, and to assess the effect of alpha-Linolenic acid (ALA) combinations treatments on MCF-7 breast cancer cell viability and intracellular reactive oxygen species (ROS).

Study Design: In-vitro study.

Place and Duration of Study: School of Biomedical Sciences, Ulster University, Coleraine (UK) September 2015 to September 2016.

Methods: Curcumin was characterized for total phenols content (TPC) and antioxidant capacity $(A O C)$ using Folin-Denis and ABTS (2,2'-Azino-bis (3-ethylbenzthiazoline-6-sulfonic acid diammonium salt) assays. MCF-7 cells were grown in DMEM phenol-red free medium $(+10 \%$ charcoal stripped foetal bovine serum) and treated with curcumin, ALA or their combinations. 
Cytotoxicity was assessed using the sulforhodamine-B assay. Intracellular ROS was monitored using 2,7-dichlorodihydroflourescein diacetate assay.

Results: Curcumin showed $42-50$ folds higher TPC and AOC compared to turmeric. Both curcumin and ALA $(0-500 \mu \mathrm{M})$ inhibited MCF-7 cells with the 50\% effective dose (EC50) equal to $32 \mu \mathrm{M}$ (curcumin) or $117 \mu \mathrm{M}(\mathrm{ALA})$. Combination of curcumin and ALA led to EC50 values of $221 \mu \mathrm{M}$ (curcumin) and $304 \mu \mathrm{M}(\mathrm{ALA})$. Isobologram analysis and values for Combination index (Cl; $\mathrm{Cl}>1.0)$ are consistent with ALA and curcumin antagonism. Changes of intracellular ROS were 20-fold higher with ALA treatment of MCF-7 compared with curcumin.

Conclusions: ALA and curcumin were each cytotoxic towards MCF-7 breast cancer cells but their combination decreases the effectiveness of each agent due to antagonistic interactions. Both ALA and curcumin produce rises in intracellular ROS for MCF-7 cells. The wider implications of such findings is that though dietary antioxidants could be beneficial on their own, antagonistic interaction with ALA, n-3 fatty acids and other ROS generating conventional anti-cancer drug could be of concern.

Keywords: Alpha-linolenic acid; curcumin; MCF-7 cells; cytotoxicity; isobologram.

\section{INTRODUCTION}

Breast cancer is the most common cancer among females in both developed and less developed countries [1]. The International Agency for Research on Cancer (IARC) reported 1.6 million new cases of breast cancer worldwide in 2012 , which is $25 \%$ of all cancer incidents [1]. About $70-75 \%$ of breast cancer is estrogen receptor and/or progesterone receptor positive [2]. Dietary polyunsaturated fatty acid (PUFA) may affect breast cancer risk by increasing endogenous estrogen levels. The presence of PUFA in adipose tissue may promote the conversion of androstenedione to estrone, inhibit estrogen binding to serum protein and consequently raise the circulating estrogen level. The type of PUFA and food source may affect breast cancer risk [2,3]. Alpha-Linolenic acid (ALA) is the primary omega-3 (n-3) PUFA consumed through food such as leafy vegetables, walnuts, soybeans, and flaxseed. Dietary ALA (18:3 n-3) is metabolised to eicosapentaenoic acid (EPA) (20:5 n-3), and docosahexaenoic acid (DHA) (22:6 n-3) through a sequence of desaturation and elongation steps [4]. PUFA were found to enhance chemotherapy and radiation treatments following lipid peroxidation to form cytotoxic products $[5,6]$. Antioxidants such as vitamin $E$, vitamin $C$ and curcumin were found to decrease cancer cell apoptosis induced by lipid peroxidation products formed from PUFA [5-7].

Plant polyphenolic antioxidants such as curcumin from turmeric may reduce the incidence of major non-communicable diseases, including cancer $[8$, 9]. Turmeric is a golden spice derived from Curcuma longa plant and used as a spice, colouring agent and in traditional medicine $[8,9]$. Curcumin accounts for $2-5 \%$ of dried weight of turmeric and its biological activity $[8,9]$. Previous research showed curcumin had anticancer effects on breast cancer cell lines, via a reduction of cell proliferation, induction of cell cycle arrest, modulating MicroRNA and promotion of apoptosis induced by reactive oxygen species (ROS) [10].

ALA shows cytotoxicity to cancer cells due partly to its lipid peroxidation products [6,7]. The antioxidant characteristics of turmeric and curcumin were also confirmed independently [8.9] and curcumin was shown to inhibit the effectiveness of anticancer agents that induce cell apoptosis via ROS activation of JNK signalling [7]. The hypothesis tested in this study was that, combination treatments involving ALA and curcumin will reduce the cytotoxicity of each agent towards MCF-7 breast cancer cells. Phenol red-free culture media [11-14] was an important feature of the experimental design. The aims of this study were to investigate the effect of ALA and curcumin on breast cancer cell proliferation individually and in combination using phenol red-free medium, and to examine the effect of ALA and curcumin on the formation of intracellular ROS in MCF-7 cells. The design of this study was such that possible interaction could be explored to a greater degree than reported previously [15].

\section{MATERIALS AND METHODS}

\subsection{Materials}

Certified organic ground turmeric (haldi) powder produced by Hatton Hill Organic Ltd. (Enfield, 
UK) was purchased from Rohan Foods Ltd. (London, UK). Curcumin powder (>98\% pure) was purchased from Sigma-Aldrich (UK). Additional analytical grade reagents were purchased from Sigma-Aldrich (Gillingham, UK) and used as received. Phosphate buffered saline (PBS) was from Oxoid Ltd (Basingstoke, UK).

\subsection{Instrumentation}

Colorimetric measurements were recorded using a UV/ Visible spectrophotometer (Ultrospec 2000, Pharmacia Biotech, Uppsala Sweden) in conjunction with 1-cm polystyrene cuvettes (Sarsted Ltd., Leicester, UK). All microplate assays involved a 96-microplate reader (VersaMax ${ }^{\mathrm{TM}}$ ELISA microplate reader, Molecular Devices, Sunnyvale, CA, USA.) used with flat-bottomed 96-well microplates (NUNC, Sigma Aldrich, UK). The florescence measured using BMG LABTECH microplate readers (FLUOstar ${ }^{\circledR}$ Omega, BMG LABTECH GmbH, Ortenberg, Germany) with black polystyrene plate (NUNC, F96 MicroWell black polystyrene plate, Thermo Fisher Scientific).

\subsection{Antioxidants Assays}

\subsubsection{Material extractions}

Curcumin powder (36.84 mg) was dissolved in $10 \mathrm{ml}$ of dimethyl sulfoxide (DMSO) to prepare $10 \mathrm{mM}$ solution. To prepare turmeric extract $36.84 \mathrm{mg}$ of turmeric powder was stirred in $10 \mathrm{ml}$ of DMSO for 60 minutes. Then $1 \mathrm{ml}$ of the mixture was transferred to $9 \mathrm{ml}$ of distilled water. The final mixture was centrifuged to remove undissolved solids.

\subsubsection{Preparation of material extract dilutions}

Turmeric or curcumin extract was diluted using PBS or distilled water and examined for total phenolic content (TPC) and antioxidant capacity $(A O C)$ as reported below. A number of dilutions were examined to achieve a linear absorbance range with each reference compound and also, to avoid formation of precipitation which result from adding concentrated extract to the assay system.

\subsubsection{Preparation of assay reference compounds}

The reference compounds for the calibration of TPC and antioxidant assays was gallic acid; for AOC analysis the reference was gallic acid, ascorbic acid or trolox. They were prepared from $1000 \mu \mathrm{M}$ solutions and diluted with PBS or distilled water to $500 \mu \mathrm{M}, 250 \mu \mathrm{M}$ and $125 \mu \mathrm{M}$, before use. All references were prepared daily before use.

\subsubsection{Evaluation of TPC using folin-denis method}

The Folin-Denis method was adapted from a previous report [16]. In brief, $50 \mu \mathrm{l}$ of curcumin or turmeric solution (or diluted sample) was added to micro-centrifuge tubes, followed by $100 \mu \mathrm{l}$ of Folin-Denis reagent and $850 \mu \mathrm{l}$ of sodium carbonate $(7.5 \% \mathrm{w} / \mathrm{v})$ reagent. The tube contents were vortexed gently and incubated for 60 minutes at $37^{\circ} \mathrm{C}$ followed by 30 minutes at room temperature. The tubes were then centrifuged using bench top centrifuge (model MSB010.CX2.5, MSE, London, UK) at 11,000 rpm $(8793 \times \mathrm{xg})$ for 5 minutes and $200 \mu \mathrm{l}$ of supernatant were carefully transferred to 96microwell plates. The absorbance was measured at $760 \mathrm{~nm}$ using a microplate reader.

\subsubsection{Evaluation of AOC}

Determination of AOC involved the 2,2'-Azinobis (3-ethylbenzthiazoline-6-sulfonic acid diammonium salt; ABTS) assay [17] as described recently [18]. ABTS solution was prepared by dissolving $27.4 \mathrm{mg}$ with $90 \mathrm{ml}$ of PBS buffer. Sodium persulfate $(20 \mathrm{mg})$ was dissolved with another $10 \mathrm{ml}$ of PBS. The ABTS working solution was generated by mixing the previous two solutions and storing in the dark at room temperature for 12-16 hours. For sample analysis and calibration, ABTS working solution was diluted with PBS buffer in order to achieve an initial absorbance of 0.85 at $734 \mathrm{~nm}$ using 1 $\mathrm{cm}$ spectrophotometer (standard colorimeter). Then, $20 \mu \mathrm{l}$ of reference compounds (explained above) were added to micro-centrifuge tubes followed with $1.48 \mathrm{ml}$ of ABTS solution. The resulting mixtures were incubated for 30 minutes at $37^{\circ} \mathrm{C}$ and $200 \mu \mathrm{l}$ samples were transferred to 96-microwell plates for absorbance readings at $734 \mathrm{~nm}$. Curcumin or turmeric solutions were pre-diluted in distilled water or PBS (dilution Factor $\left.\left(D_{F}\right)=10-1000\right)$ and analysed similarly.

\subsection{Cytotoxicity Assay}

\subsubsection{Cell lines and maintenance of cell culture}

Estrogen receptor positive (ER+) MCF-7 breast cancer cells (American Type Culture Collection; 
LGC Standards - Teddington, Middlesex, UK) were cultured in Dulbecco's modified Eagle's medium (DMEM; GIBCO) with 10\% foetal bovine serum (FBS), $1 \% \mathrm{w} / \mathrm{v}$ penicillin streptomycin (Pen Strep) and $1 \%$ minimum essential medium non-essential amino acids (MEM NEAA). Culture flasks and 96-microwell plates were incubated in a humidified incubator at $37^{\circ} \mathrm{C}$ in $\mathrm{O} 295 \%$ and $\mathrm{CO} 25 \%$ (LEEC Research $\mathrm{CO}_{2}$ Incubator, LEEC Ltd., Nottingham, UK). Cells were washed with PBS three time, trypsinized, then transferred to phenol red free medium (DMEM F12 phenol free; GIBCO) with $10 \%$ protein charcoal stripped FBS, USDA-approved, $1 \% \mathrm{w} / \mathrm{v}$ penicillin streptomycin (Pen Strep) and $1 \%$ minimum essential medium non-essential amino acids (MEM NEAA). The trypsinized cells were counted using a NucleoCounter (NC-3000, ChemoMetec, Allerod, Denmark) and seeded in 96-microwell plates $(10,000$ cells/ well) with $50 \mu \mathrm{l}$ of phenol-red free culture medium overnight to allow cell attachment. Cell viability was monitored using a sulforhodamine method (see below).

\subsubsection{Curcumin and ALA preparation for cytotoxicity studies}

Curcumin stock solutions were prepared as described in section 2.3. Alpha-Linolenic acid (ALA) was diluted in DMSO to make a $10 \mathrm{mM}$ stock solution. The stock solutions were diluted in phenol red-free culture medium, and coldsterilised using $0.20 \mu \mathrm{m}$ cellulose acetate filters. Varying concentration of curcumin or ALA ( $0-500$ $\mu \mathrm{M})$ in cell culture media were applied to the cells and incubated at $37^{\circ} \mathrm{C}$ for 3 days and 6 days. The final concentration of DMSO in the treated wells was non-toxic to MCF-7 cells (less than $1 \%$ ) [15]. In the control study, cells were treated with culture medium only. For the combination studies, cells were treated with a range of $\operatorname{ALA}(0-500 \mu \mathrm{M})$ or curcumin $(0-500$ $\mu \mathrm{M})$ but in the presence of a fixed concentration of the second agent as described in ref [19].

\subsubsection{Assessing cell viability using sulforhodamine B (SRB) assay}

The SRB assay is a colorimetric assay to measure cell numbers by detecting cell proteins [20]. After curcumin or ALA treatments, the cells were fixed with $100 \mu \mathrm{l}$ of cold $10 \%(\mathrm{w} / \mathrm{v})$ trichloroacetic acid and incubated at $5{ }^{\circ} \mathrm{C}$ for 60 minutes. Then, the microplates were washed with tap water four times and allowed to air-dry. After that, the cells were stained with $100 \mu \mathrm{l}$ per well of $0.06 \%$ SRB dye solution $(1 \% \mathrm{w} / \mathrm{v}$ in acetic acid) for 30 minutes at room temperature. The cells were rinsed four times with $100 \mu \mathrm{l}$ per well of $1 \%(\mathrm{v} / \mathrm{v})$ acetic acid to remove unbound stain. When the plates were dried, Trizma-base (200 $\mu \mathrm{l} /$ well, $10 \mathrm{mM}$ ) was added to solubilise SRB dye, and the plate was shaken for 5 minutes on an orbital shaker at speed of $180 \mathrm{revs} / \mathrm{min}$. Finally, the absorbance was measured using a plate reader at $564 \mathrm{~nm}$.

\subsection{Determination of Intracellular ROS Using 2, 7-dichlorodihydroflourescein Diacetate (DCFH-DA) Assay}

The DCFH-DA assay is for assessing intracellular ROS. The assay was performed according to previous reports [21] with slight modification. In brief, a stock solution of DCFHDA was made by dissolving $10 \mathrm{mg}$ of DCFH-DA powder into $1 \mathrm{ml}$ DMSO. The working solution was prepared by diluting $49 \mu \mathrm{l}$ of DCFH-DA stock solution with $20 \mathrm{ml}$ of Hanks salt solution and filter sterilizing with $0.20 \mu \mathrm{m}$ cellulose acetate filters. MCF-7 cells used for ROS testing were seeded in 96-wells plate and allowed to attach overnight. The cells were washed using Hanks salt solution $(200 \mu \mathrm{l} \times 1)$ and treated with DCFHDA working solution $(50 \mu \mathrm{l})$. After 45 minutes' incubation at $37^{\circ} \mathrm{C}$, the cells were washed with phenol red-free culture medium $(200 \mu \mathrm{l})$ and then treated with various concentrations $(0.5-500 \mu \mathrm{M})$ of ALA or curcumin and also the combinations ALA and curcumin determined from the single treatment studies. Then, the plates were incubated at $37^{\circ} \mathrm{C}$ for 60 minutes, and fluorescence was measured at $485 \mathrm{~nm}$ (excitation) and $520 \mathrm{~nm}$ (emission) wavelengths on a microplate reader.

\subsection{Data Analysis}

\subsubsection{TPC and AOC calibration graphs}

Absorbance readings for reference compounds were exported to Microsoft Office Excel software for graphing and analysing. Calibration graphs were constructed by plotting absorbance versus the concentration of references compounds in the assay system (M) on the $x$-axis. Data points were fitted with a linear regression trend line $(y=$ x. GRAD) and apparent molar absorptivity (GRAD) was determined from the graph slope as described before [15,18].

\subsubsection{TPC and AOC calculations from spectrophotometric data}

The TPC and AOC of turmeric and curcumin were determined using the formula $[15,18]$; 
TPC or $\mathrm{AOC}=$

$$
\frac{\Delta A}{G R A D} * \frac{A_{V}}{S p_{v}} * \mathrm{D}_{F} * \frac{1}{C_{\text {ext }}} \times 10^{5}
$$

where $\Delta \mathrm{A}$ is the absorbance change corrected for the reagent blank, $A_{v}$ is the total assay volume $(1000 \mu \mathrm{l}), S p_{v}$ is the sip volume $(50 \mu \mathrm{l})$ of sample analysed, $C_{\text {ext }}$ is the concentration of turmeric or curcumin solutions $(g / l), D_{F}$ for undiluted solutions $=1$, and GRAD is the slope obtained from gallic acid and/or ascorbic acid and trolox calibration graphs; the results are expressed as g/100 g DW using gallic acid equivalent (GAE), ascorbic acid equivalent (ASC:), trolox equivalent (TE). The AOC values with trolox are cited as trolox equivalent antioxidant capacity (TEAC) $[17,18]$.

\subsubsection{Cell viability and statistical analysis}

Cells viability experiments were repeated on 2 different occasions with 12-24 replications per drug concentration. Microsoft Office Excel software was used for primary data operation and percentage of cell viability (CV\%) calculation according to formula (2) below $[15,18]$;

CV $(\%)=$

$\left(A-A_{\text {medium }}\right){ }^{*} 100 /\left(A_{\text {control }}-A_{\text {medium }}\right){ }^{*} 100$

where $A=$ absorbance for cells treated with curcumin/ ALA, A medium = absorbance for the culture medium, $A_{\text {control }}=$ absorbance of cells treated with culture medium $[15,18]$. The results were expressed as mean $\pm S D$, and statistically significant differences were determined by 1 -way
ANOVA using IBM SPSS v22. Post-hoc analysis for separation of means was by Tukey's test. Probability values $(P)$ less than 0.05 were considered to be statistically significant. Paired ttest were performed on a calculator at www.graphpad.com to test statistically significant differences between EC50 (half maximal effective dose of treatment compound) values.

\section{RESULTS}

\subsection{TPC and AOC for Turmeric and Curcumin}

Fig. 1 shows the calibration graph for TPC and $A O C$ determination using the Folin-Denis and ABTS assays, respectively. In TPC the reference compound was gallic acid. In the ABTS assay, three reference compounds were used, Gallic acid, ascorbic acid and trolox. Each reference compound had a linear response with a coefficient of regression $\left(R^{2}\right)>0.97$. The data were fitted with a straight line equation $(Y=x$. GRAD), where $Y=$ absorbance, $x=$ concentration of reference agents, and GRAD = slope of the line.

Table 1 compares TPC and antioxidant capacity for curcumin and turmeric in terms of $100 \mathrm{~g}$ of dry weight. The value for TPC for curcumin was approximately 50 times higher than turmeric. Similarly, in the antioxidant capacity, curcumin was 42 times higher in equivalent to gallic acid and 5 times higher in equivalent of ascorbic acid and trolox (Table 1).

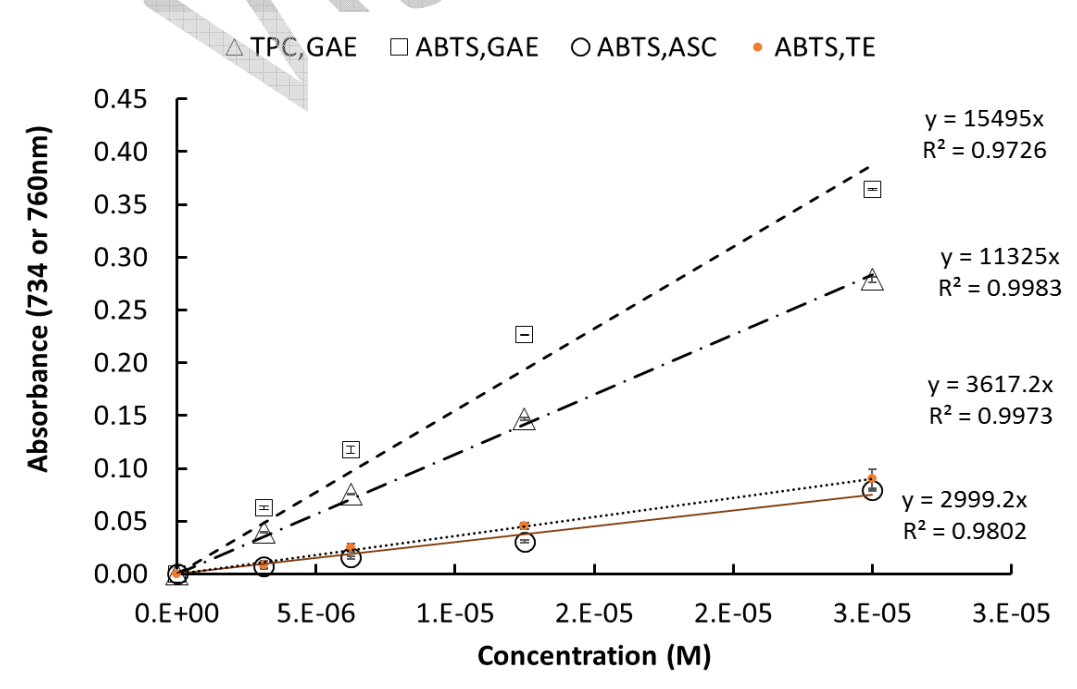

Fig. 1. Calibration graphs for total phenol content and antioxidant capacity assays

$T P C, G A E=$ Total phenol content with gallic acid as reference. ABTS, GAE = antioxidant capacity with gallic acid reference, $A S C=$ ascorbic acid or $T E=$ trolox as references 


\subsection{Cell Viability Changes with ALA or Curcumin}

Phenol red is a $\mathrm{pH}$ indicator added frequently to cell culture media [11-14]. However, phenol red can also acts as an antioxidant, a weak estrogen receptor stimulator, a promotor for $\mathrm{MCF}-7$ proliferation and enhancer of cell stability against chemotherapy at neutral or low $\mathrm{pH}[12,13]$. Interestingly, phenol red was also found to be cytotoxic towards MCF-7 cells at high concentrations and at $\mathrm{pH} 7.6-8.0$ [14]. In the present study, phenol red-free media was used to avoid possible interferences in cell-based assays. Fig. 2 shows the treatment of MCF-7 cells with ALA $(0.005-5 \mu \mathrm{M})$ for 3 days led to significant increases in cell viability compared to the non-treated cells. However, cell viability decreased significantly at higher ALA (50-500 $\mu \mathrm{M})$ concentrations. With 6 -days treatment cell viability remained stable and an inhibitory effect was observed at $50-500 \mu \mathrm{M}$ of ALA. The dose of ALA necessary to reduce cell viability by $50 \%$ (EC50) with 3 and 6-days treatments is shown in Table 2.

Fig. 3 shows that the treatment of MCF-7 cells with curcumin for 3 or 6 days produced no significant changes in cell viability at the concentration of $0.005-5 \mu \mathrm{M}$ compared to the non-treated cells. However, cell viability decreased at $50-500 \mu \mathrm{M}$. The effective dose of curcumin for $50 \%$ inhibition (EC50) value decreased from 3-days to 6-days treatment, 32 to $26 \mu \mathrm{M}$, respectively. The summary of EC50 values for curcumin and for curcumin combination studies is provided in Table 2.

Table 2. Potency of ALA, curcumin and their combinations for MDA-MB-231 cell inhibition expressed as EC50

\begin{tabular}{lll}
\hline Treatment & $\begin{array}{l}\text { EC50 } \\
\text { (3 days) }\end{array}$ & $\begin{array}{l}\text { EC50 } \\
\text { (6 days) }\end{array}$ \\
\hline ALA & $117 \pm 11.0^{* A}$ & $62 \pm 4.3^{\mathrm{B}}$ \\
Curcumin & $32 \pm 3.6^{* \mathrm{C}}$ & $26 \pm 2.7^{\mathrm{D}}$ \\
ALA+ Curcumin $(16 \mu \mathrm{M})^{\perp}$ & $304 \pm 41.0$ \\
Curcumin + ALA & $221 \pm 2.8^{*}$ \\
$(100 \mu \mathrm{M})^{\perp}$ & \\
\hline$A L A=$ alpha Linolenic acid, EC50 $=$ dose for $50 \%$ \\
effectiveness, $(\Theta)$ SEM= standard error of mean. \\
$N=24$ data points from two independent studies. \\
Rows and columns with different letters are \\
significantly different $(P=0.05)$. $^{\perp}$ Combination studies \\
\multicolumn{2}{c}{ (see text for details) }
\end{tabular}

\subsubsection{Combination studies}

When cells were treated with a range of ALA concentrations and a fixed curcumin (16 uM) combination, the experimental EC50 value was $304 \mu \mathrm{M}$ which is significantly higher than the value of $117 \mu \mathrm{M}(P=0.0415)$ for treating cells with ALA alone (Table 2). Similarly, when cells were treated with curcumin in combination with ALA (fixed $100 \mu \mathrm{M}$ ) for 3 days the experimentally observed EC50 for curcumin increased by nearly 7-fold compared to the EC50 for curcumin treatment alone $(P=0.0001)$. The results for combination studies are summarized in Table 2.

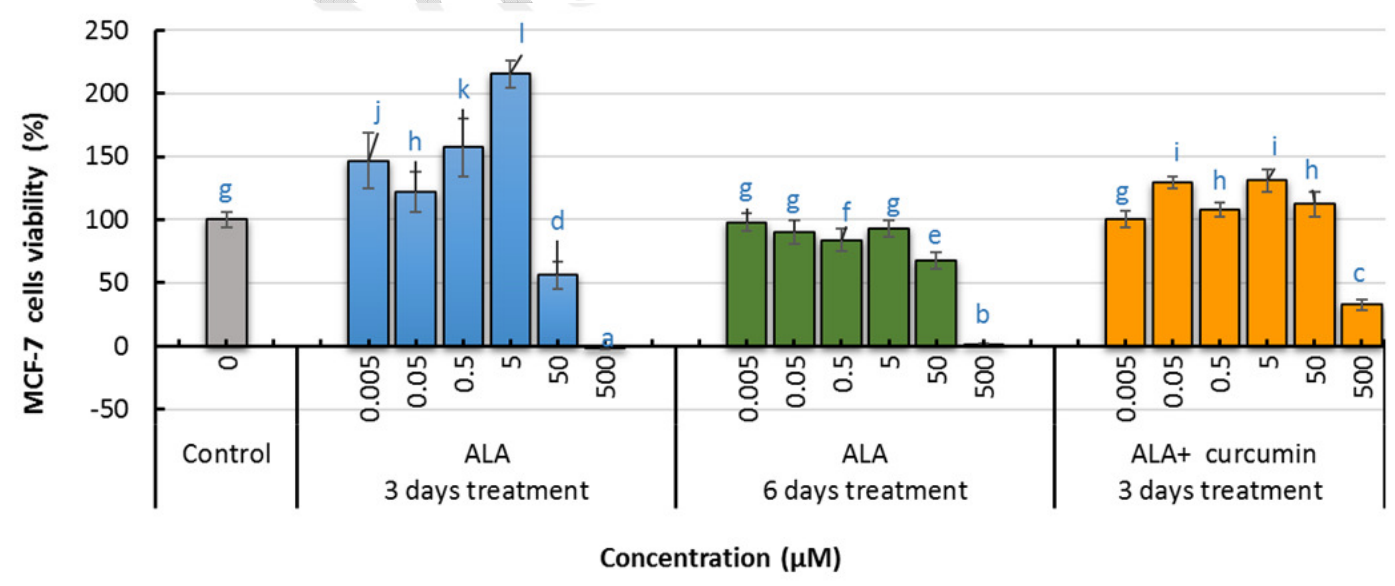

Fig. 2. Effect of $\alpha$-linolenic acid (ALA) and its combination with curcumin on MCF-7 cell viability

MCF-7 cells were treated with 0-500 um ALA + fixed curcumin $(16 \mu \mathrm{M})$. Bars show mean $+/-$ SEM. Within each panel different letters indicate statistical significant differences $(P<0.05)$ 


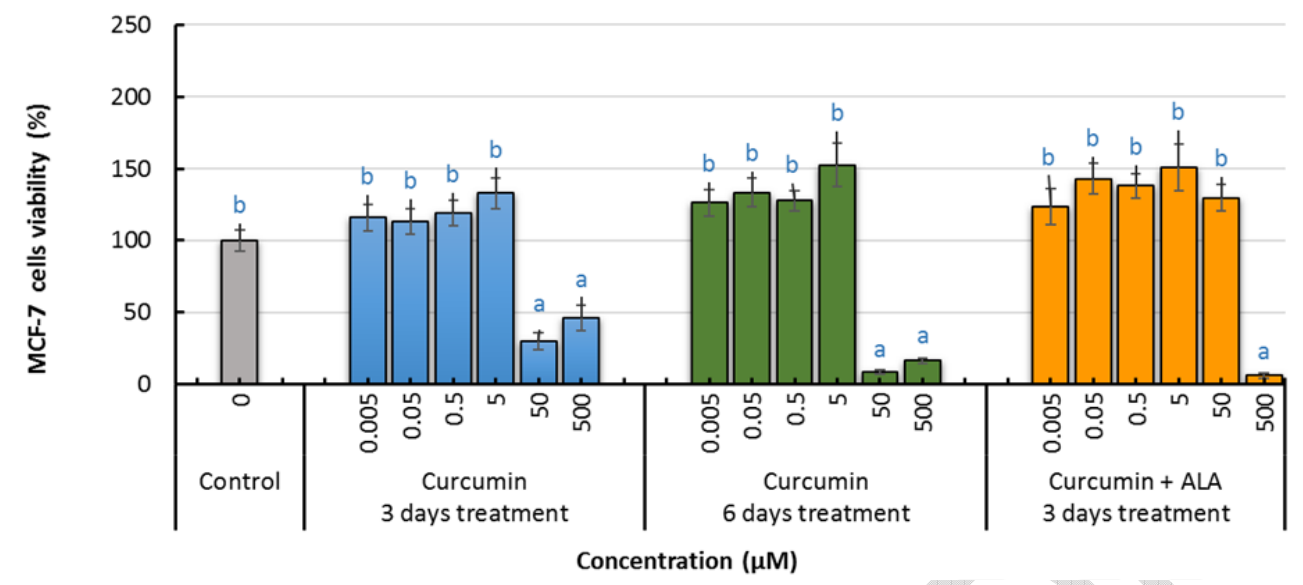

Fig. 3. Effect of curcumin and its combination with ALA on MCF-7 cell viability

MCF-7 cells were treated with 0-500 $\mu \mathrm{M}$ curcumin or curcumin + fixed ALA (100 $\mu \mathrm{M})$. Bars show mean +/- SEM. Within each panel different letters indicate statistical significant differences $(P<0.05)$

An isobologram analysis was conducted to determine iso-effective concentrations of ALA plus curcumin which would produce the same effects as each component alone, assuming there were neither synergistic nor antagonistic interactions. The analysis involved eq. (3) adapted from reference [19];

$$
\begin{aligned}
& d_{50} A L A=\alpha 117(\mu \mathrm{M}) \\
& d_{50} \text { CURC }=(1-\alpha) 32.6(\mu \mathrm{M})
\end{aligned}
$$

where $\alpha=$ fraction of ALA in a mixture, $1-\alpha$ is the fraction of curcumin, $d_{50} A L A$ and $d_{50} C U R C$ are the iso-effective concentrations of ALA or curcumin which when mixed will produce $50 \%$ cell growth inhibition. Fig. 4 shows the isobologram for ALA and curcumin.

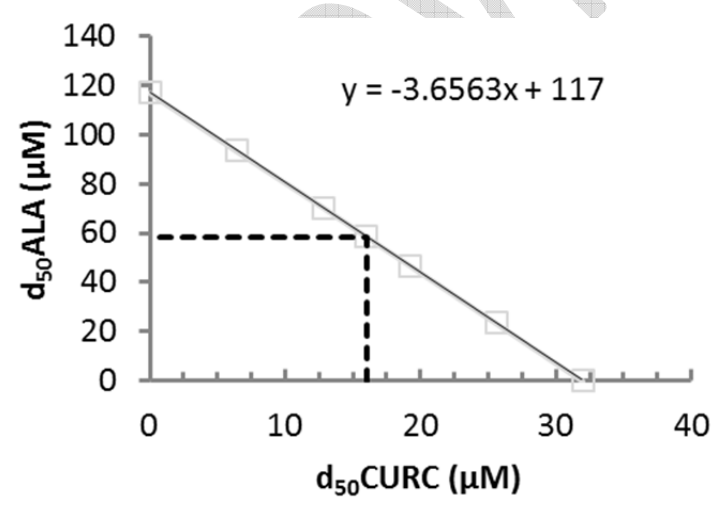

Fig. 4. Isobologram for alpha-linolenic acid (ALA) and curcumin (CURC) mixtures Graph shows iso-effective doses of two agents required for $50 \%$ inhibition of $M C F-7$ cell growth under present conditions of study. $d_{50} A L A$ and $d_{50}$ CURC are iso-effective concentrations of ALA or curcumin, respectively (see text for details)
The continuous line from Fig. 4 shows the isoeffective doses for ALA and curcumin. From Fig. 4, it can be seen that the EC50 value for ALA and curcumin are 117 and $32 \mu \mathrm{M}$, when used alone. However, combination treatments are predicted to decrease the effective dose for each agent. For example, a combination treatment using $16 \mu \mathrm{M}$ curcumin and $58 \mu \mathrm{M}$ ALA is predicted to achieve the same $(50 \%)$ inhibition of MCF-7 cells inhibition as $117 \mu \mathrm{M}$ ALA or 32 $\mu \mathrm{M}$ curcumin used each on their own. An alternative interpretation of information from Fig. 4 is that the $50 \%$ effective dose for ALA should be $58 \mu \mathrm{M}$ in the presence of $16 \mu \mathrm{M}$ curcumin (cf. dotted line in Fig. 4). The predictions can be contrasted with the experimentally observed EC50 value from the ALA combination study $\left(d_{50} A L A\right)$ of $304 \mu \mathrm{M}$ (Table 2$)$.

The nature of interactions between ALA and curcumin were also evaluated in terms of a combination index $(\mathrm{Cl})$ defined from the relation below [19];

$$
C I=\frac{d_{50} A L A}{E C 501}+\frac{d_{50} C U R C}{E C 502}
$$

where, $\quad d_{50} A L A$ and $d_{50}$ CURC refer to experimental EC50 values from combination studies, and $\mathrm{EC} \mathrm{O}_{1}$ and $\mathrm{EC} \mathrm{O}_{2}$ are values for each agent alone; $\mathrm{Cl}<1.0$ is indicative of synergism, $\mathrm{Cl}=1$ indicates no interactions, $\mathrm{Cl}$ $>1,0$ shows antagonism. As an illustration the combination study for ALA (with curcumin fixed) yields $\mathrm{Cl}=(304 / 117)+(16 / 32)=3.0$. A similar treatment from the curcumin combination study shows, $\mathrm{Cl}=5.0$. In both cases $\mathrm{Cl}>1.0$ and such results are indicative of antagonism between these agents [19]. 


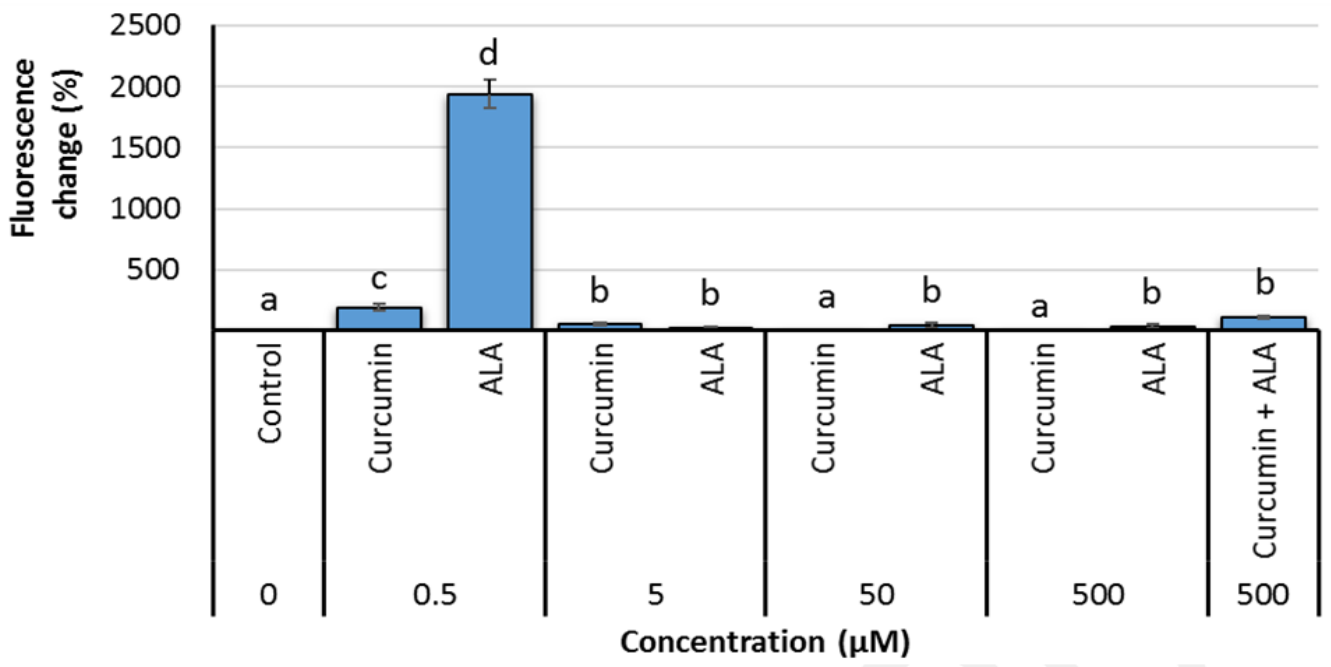

Fig. 5. Effect of curcumin and $\alpha$-linolenic acid and curcumin on intracellular ROS level in MCF-7 cells

MCF-7 treated with curcumin, ALA (0.5-500 $\mu \mathrm{M})$ or a combination of both $500 \mu \mathrm{M}$ for 1 hour. Bars show mean +/SEM. Bars with different letters indicate statistical significant differences between all groups, tested by ANOVA $(P<0.05) . \quad A L A=$ alpha-Linolenic acid

\subsection{Intracellular ROS Level}

The intracellular ROS levels for MCF-7 cells treated with curcumin and/ or ALA are shown in Fig. 5. When cells were treated with $0.5 \mu \mathrm{M}$ of ALA there was a 20 - fold greater increases in ROS compared with increase seen with curcumin. At concentrations of $5-500 \mu \mathrm{M}$ there was a surprising drop in ROS compared to values at $0.5 \mu \mathrm{M}$. The combination of curcumin and ALA resulted in a slight increase of ROS level relative to $500 \mu \mathrm{M}$ curcumin individually but not relative to the ROS level produced by 500 $\mu \mathrm{M}$ ALA.

\section{DISCUSSION}

In a prior investigation we demonstrated that the anticancer effect of ALA towards MCF-7 cells was lower in the presence of antioxidant extracts [15]. The current study reassessed this issue, using phenol red-free medium and combination treatments designed to allow quantitative analysis of interactions. As part of the current study, we also assessed the TPC and AOC of curcumin and turmeric. Previous literature values for TPC or AOC of turmeric indicated a range of values probably because of differences the solvent used for extraction [22,23].

For two varieties of Curcuma longa dried rhizome extracted with $80 \%$ aqueous methanol, the TPC was 2.13-2.16 g GAE/100 DW [22] and AOC determined using the ABTS assay was 18-22 mmol TEAC/100 g DW [22]. Curcuma longa dried rhizome extracted with $80 \%$ aqueous ethanol showed TPC of $1.72 \pm 0.12 \mathrm{~g} \mathrm{GAE} / 100 \mathrm{~g}$ DW and AOC of $19.5 \pm 0.45 \mathrm{mmol}$ TEAC/100 g DW [23]. Another study also found the TPC for Curcuma longa was $0.497-0.746 \mathrm{~g} \mathrm{GAE} / 100 \mathrm{~g}$ DW when using alcohol/water mixtures as extraction solvent [24]. For comparison, the turmeric sample in this study had TPC of $3 \mathrm{~g}$ GAE/100 g DW (Table 1) in agreement with previous reports, whilst the AOC using DMSO as extraction solvent was $\sim 10$ fold higher than reported previously.

Curcumin dissolved with methanol had a TPC ranging from $8.7 \mathrm{~g} \mathrm{GAE} / 100 \mathrm{~g}$ DW [15] to $11.5 \mathrm{~g}$ $\mathrm{GAE} / 100 \mathrm{~g}$ [25] and $A O C$ was $23.4 \mathrm{mmol}$ TEAC/100 g DW [15]. By comparison the current study shows $\sim 20$ fold higher TPC value and the AOC value was $\sim 50$ fold higher than reported previously. It is feasible that the choice solvent may be important because of difference in polarity influences the solubility of chemical components, extraction yield for antioxidants, TPC and AOC [26,27].

All cytotoxicity testing used DMSO $(<1 . \%$ final concentration) as solvent. This present study also adopted phenol red-free medium in order to avoid possible confounding effects from phenol red which possess estrogenic activity and AOC. Previous studies using MCF-7 cells with phenol 
red present found the EC50 value for curcumin was $9.8 \mu \mathrm{M}$ and $9.7 \mu \mathrm{M}$ after 48 and 96-hours exposure, respectively [28]. Another study reported the curcumin EC50 value of $60 \mu \mathrm{M}$ for 48-hour treatment [29]. More recent investigations found curcumin EC50 value with MCF-7 cells was, $31 \mu \mathrm{M}, 21 \mu \mathrm{M}$ or $11 \mu \mathrm{M}$ when using 24,48 or 72 -hours treatment, respectively [30]. Our previous study using MCF-7 cells in phenol red medium showed curcumin EC50 value was $7 \mu \mathrm{M}$ for 72 -hour exposure [15] whilst in the present study curcumin E50 was $32.6 \mu \mathrm{M}$ which is nearly 5 -fold higher than observed previously.

The number of reports dealing with the effect of ALA on MCF-7 cells is limited at present $[15,31$ 33]. There was a $55 \%$ inhibition of MCF-7 cells exposed to $75 \mu \mathrm{M}$ ALA for 2 days in phenol redfree medium [31] and treatment with $50 \mu \mathrm{M}$ of ALA produced $33 \%$ inhibition [32]. In a previous study from our laboratory, the EC50 for ALA with 3-days treatment in phenol red containing medium was $50 \mu \mathrm{M}$ [15] which is significantly lower than the EC50 (117 $\mu \mathrm{M}$ ALA) from the present study; moreover, increasing the treatment time from 3 to 6 days led to a decline in EC50 to $62 \mu \mathrm{M} \quad(P=0.0001)$. Some differences in EC50 may arise from differences in experimental details such as, initial number of cells in each well, length of time allowed for cells to adhere to microplates, and whether there are changes of culture medium during the treatment period. Interestingly, the range of doses for ALA inhibition of MCF-7 cells are thought to be attainable under physiological conditions [32] following dietary supplementation with PUFA when circulating plasma levels may reach 100 $200 \mu \mathrm{M}$ [32].

The former design also did not allow isobolograms and $\mathrm{Cl}$ analyses. In the present study, $\mathrm{Cl}>1.0$ which is consistent with antagonism between ALA and curcumin. The current results are consistent with a drop in the potency for ALA or curcumin when used as a combination. In broad terms, a low value for EC50 (Table 2) is indicative of greater potency. The combination treatments produced 2.6-fold and 7.0-fold reductions of potency for ALA and curcumin, respectively. More extensive discussion of potency changes will require a wider range of studies over a wider range of concentrations

In line with the initial working-hypothesis, the antagonisms between ALA and curcumin could arise from the tendency for ALA to undergo peroxidation and from the known antioxidant properties of curcumin $[5,6]$ which would counter oxidative processes. In support of these views curcumin has been shown to reduce the effectiveness of conventional anti-cancer drugs which increase intracellular ROS [7]. Alternative models could emerge to account for such results. For example, it is known that ALA inhibits MCF-7 cell growth via a range of mechanism, including the formation of ALA membrane phospholipids and alterations of growth and gene expression $[5,31,33]$. Curcumin also has multiple effects on cancer cells $[8,9,28]$ and so other routes for antagonism could be possible. Interestingly, curcumin and docosahexaenoic acid were found interact antagonistically for several breast cancer cell phenotypes but synergistic in the case of another [34].

Intracellular ROS levels were increased in MCF7 after exposure to ALA, curcumin, and their combination for 1 hour using DCFH-DA assay. This finding (Fig. 5) is consistent with our working hypothesis, which is that ALA promotes intracellular ROS [12-15]. However, the intracellular ROS increases occurred at low concentrations $(0.5 \mu \mathrm{M})$ of ALA and curcumin compared to those required to reduce cell viability ( 32-100 $\mu \mathrm{M}$; Table 2). Apparently, results from the DCFH-DA assay cannot be compared directly with cell viability results, maybe because of the difference in exposure period ( $1 \mathrm{hr}$ versus 3 days). It was suggested that DCFH-DA assay may provide information related to stress within cells prior to injury [35].

This study was an in-vitro study with the usual limitations arising from the use of isolated cells. Since ALA appeared more effective with prolonged cell exposure then duration of combination studies could be extended. The intracellular ROS assays could also be easier to interpret if these used a longer study time. This paper extends previous reports that ALA and curcumin exhibit antagonism with respect of cytotoxicity in-vitro [15]. It is essential to examine such relations using a wider range of cancer cell types. Finally, the possible role of phenol red medium in cytotoxicity assays, particularly when using estrogen positive cells lines is also worthy of more in-depth investigations.

\section{CONCLUSION}

This study showed that curcumin has a higher content of TPC and AOC compared to turmeric. Both curcumin and ALA were cytotoxic towards MCF-7 cells. However, the combination of 
curcumin and ALA reduced the effectiveness of each agent. Treatment of MCF-7 cells with ALA or curcumin produced significant increases of intracellular ROS but the former was 20 -fold higher. The findings of this study suggest there are antagonistic interactions between ALA and curcumin with respect to their cytotoxicity towards MCF-7 breast cancer cells. Many conventional anticancer drugs are believed to function by increasing ROS and some of these were found to be antagonized by curcumin [7]. Caution is warranted because present results do not provide useful information about the effects of sequential treatments using curcumin and ALA. It is also necessary to study the observed effects in animal models. With such reservations in mind, one implication of the present findings is that though dietary antioxidants could beneficial on their own there could be scope for antagonism with ALA, n-3 fatty acids, or other ROS dependent therapy [7]. There is an ongoing need to for more research into the effect other dietary antioxidants on anticancer agents.

\section{ACKNOWLEDGEMENTS}

Author TA expresses profound gratitude to her parents and spouse for providing unfailing support and encouragement throughout years of study, research and writing. This accomplishment would not have been possible without them.

\section{COMPETING INTERESTS}

Authors have declared that no competing interests exist.

\section{REFERENCES}

1. Ferlay J, Soerjomataram I, Dikshit R, Eser S, Mathers C, Rebelo M, Parkin DM, Forman D, Bray F. Cancer incidence and mortality worldwide: Sources, methods and major patterns in GLOBOCAN 2012. Int. J. Can Journal of Cancer. 2015;136(5): E359-86.

PMID: 25220842

DOI: $10.1002 /$ ijc.29210

2. Bak MJ, Das Gupta S, Wahler J, Suh N. Role of dietary bioactive natural products in estrogen receptor-positive breast cancer. Semin Cancer Biol; 2016 (In press).

Available:http://www.sciencedirect.com/sci ence/article/pii/S1044579X16300050
3. Kotepui M. Diet and risk of breast cancer.

Contemp Oncol (Pozn). 2016;20(1):13-19.

PMCID: PMC4829739;

DOI: $10.5114 /$ wo. 2014.40560

4. Anderson BM, Ma D. Are all n-3 polyunsaturated fatty acids created equal? Lipids Health Dis. 2009;8(33):1-20. PMC3224740.

DOI: 10.1186/1476-511X-8-33

5. Biondo PD, Brindley DN, Sawyer MB, Field CJ. The potential for treatment with dietary long-chain polyunsaturated n-3 fatty acids during chemotherapy. J Nutr Biochem. 2008;19(12):787-796.

PMID: 18602809

DOI: 10.1016/j.jnutbio.2008.02.003.

PMID: 18602809

DOI: 10.1016/j.jnutbio.2008.02.003

6. Das UN. Essential fatty acids enhance free radical generation and lipid peroxidation to induce apoptosis of tumor cells. Clin Lipidol. 2011;6(4):463-489.

7. Somasundaram S, Edmund NA, Moore DT, Small GW, Shi YY, Orlowski RZ. Dietary curcumin inhibits chemotherapy-induced apoptosis in models of human breast cancer. Cancer Research. 2002;62(13): 3868-75.

PMID: 12097302

8. Kocaadam B, Sanlier N. Curcumin, an active component of turmeric (Curcuma longa), and its effects on health. Crit Rev Food Sci Nutr. 2015;1-29.

PMID: 26528921

DOI: 10.1080/10408398.2015.1077195

9. Gupta SC, Sung B, Kim JH, Prasad S, Li SY, Aggarwal BB. Multitargeting by turmeric, the golden spice: From kitchen to clinic. Mol Nutr Food Res. 2013; 57(9):1510-1528.

PMID: 22887802

DOI: 10.1002/mnfr.201100741

10. Wang $Y, Y u$ J, Cui $R$, Lin J, Ding $X$. Curcumin in treating breast cancer. A review. J Lab Autom. 2016;1-9.

PMID: 27325106

DOI: $10.1177 / 2211068216655524$

11. Lewinska A, Wnuk M, Slota E, Bartosz G. Total anti-oxidant capacity of cell culture media. Clin Exp Pharmacol Physiol. 2007;34(8):781-786.

PMID: 17600557

DOI: 10.1111/j.1440-1681.2007. 04637.x 
12. Berthois $Y$, Katzenellenbogen JA, Katzenellenbogen BS. Phenol red in tissue culture media is a weak estrogen: Implications concerning the study of estrogen-responsive cells in culture. Proc Natl Acad Sci U S A. 1986;83(8):2496. PMCID: PMC323325

13. Wesierska-Gadek J, Schreiner $\mathrm{T}$, Gueorguieva M, Ranftler C. Phenol red reduces ROSC mediated cell cycle arrest and apoptosis in human MCF-7 cells. J Cell Biochem. 2006;98(6):1367-1379. PMID: 16741967

DOI: $10.1002 / j c b .20960$

14. Grady LH, Nonneman DJ, Rottinghaus GE, Welshons WV. Ph-dependent cytotoxicity of contaminants of phenol red for MCF-7 breast-cancer cells. Endocrinology. $1991 ; 129(6): 3321-3330$.

PMID: 1954908

DOI: 10.1210/endo-129-6-3321

15. Cheung TKN, Singh Nigam $P$, OwusuApenten R. Antioxidant activity of curcumin and neem (Azadirachta indica) powders: Combination studies with ALA using MCF7 breast cancer cells. J. Appl. Life Sci. Int. 2016;4(3):1-12.

DOI: $10.9734 / J A L S I / 2016 / 22273$

16. Ainsworth E, Gillespie K. Estimation of total phenolic content and other oxidation substrates in plant tissues using folinciocalteu reagent. Nat Protoc. 2007; 2(4):875-877.

PMID: 17446889

DOI: $10.1038 /$ nprot.2007.102

17. Walker RB, Everette JD. Comparative reaction rates of various antioxidants with ABTS radical cation. J Agric Food Chem. 2009;57(4):1156-1161.

PMID: 19199590

DOI: $10.1021 /$ jf8026765

18. Chan YM, Cheng NK, Singh Nigam $P$, Owusu-Apenten R. Effect of $\mathrm{pH}$ on the radical quenching capacity of tea infusions using the ABTS•+ assay. J. Appl. Life Sci. Int. 2016;6(2):1-8.

DOI: 10.9734/JALSI/2016/27235.

19. Breitinger HG. Drug synergy-mechanisms and methods of analysis. In: Acree W, editor. Toxicity and Drug Testing. Rijeka, InTech; 2012.

20. Vichai V, Kirtikara K. Sulforhodamine B colorimetric assay for cytotoxicity screening. Nature Protocols. 2006;1(3): 1112-1116.

PMID: 17406391

DOI: $10.1038 /$ nprot.2006.179
21. Wang $H$, Joseph JA. Quantifying cellular oxidative stress by dichlorofluorescein assay using microplate reader1. Free Radic Biol Med. 1999;27(5-6):612-616. PMID: 10490282

Available:http://dx.doi.org/10.1016/S08915849(99)00107-0

22. Surveswaran S, Cai YZ, Corke H, Sun M. Systematic evaluation of natural phenolic antioxidants from 133 Indian medicinal plants. Food Chem. 2007;102(3):938-53.

23. Wojdyło A, Oszmiański J, Czemerys R. Antioxidant activity and phenolic compounds in 32 selected herbs. Food Chem. 2007;105(3):940-949.

Available:http://dx.doi.org/10.1016/ifoodch em (2007.04.038)

24. Nisar T, Nisar M, Raza A, Safdar M, Iftikhar F, Waheed M. Estimation of total phenolics and free radical scavenging of turmeric (Curcuma longa). AmericanEurasian J. Agric. \& Environ. Sci. 2015;15(7):1272-1277.

DOI: 10.5829/idosi.aejaes.2015.15.7.9527

25. El-Beshbishy $\mathrm{H}$, Mohamadin AM, AbdelNaim A. Experimental study: In-vitro evaluation of the antioxidant activities of grape seed (vitis vinifera) extract, blackseed (Nigella sativa) extract and curcumin. J T U Med Sc. 2009;4(1):23-35. Available:http://dx.doi.org/10.1016/S16583612(09)70078-2

26. Mokrani A, Madani K. Effect of solvent, time and temperature on the extraction of phenolic compounds and antioxidant capacity of peach (Prunus persica L.) fruit. Separation and Purification Technology. 2016;162:68-76.

Available:http://dx.doi.org/10.1016/i.seppur .2016 .01 .043

27. Bhebhe $M$, Muchuweti M, Füller TN, Chipurura B. Effect of solvent type on total phenolic content and free radical scavenging activity of black tea and herbal infusions. Food Analytical Methods. 2016;9(4):1060-1067.

DOI: $10.1007 / \mathrm{s} 12161-015-0270-z$

28. Jiang $M$, Huang $O$, Zhang $X$, Xie $Z$, Shen $A$, Liu $H$, et al. Curcumin induces cell death and restores tamoxifen sensitivity in the antiestrogen-resistant breast cancer cell lines MCF-7 /LCC2 and MCF-7/LCC9. Molecules. 2013;18(1):701-720.

DOI: 10.3390/molecules 18010701 
29. Lv ZD, Liu XP, Zhao WJ, Dong Q, Li FN, Wang HB, Kong B. Curcumin induces apoptosis in breast cancer cells and inhibits tumor growth in vitro and in vivo. Int J Clin Exp Pathol. 2014;7(6):28182824.

PMCID: PMC4097278

30. Mirakabad T, Sadat F, Abolfazl A, et al. A comparison between the cytotoxic effects of pure curcumin and curcumin-loaded PLGA-PEG nanoparticles on the MCF-7 human breast cancer cell line. Artif Cells Nanomed Biotechnol. 2016;44(1):423-430. PMID: 25229832.

DOI: $10.3109 / 21691401.2014 .955108$

31. Wiggins A, Kharotia S, Mason JK, Thompson LU. Alpha-linolenic acid reduces growth of both triple negative and luminal breast cancer cells in high and low estrogen environments. Nutr Cancer. 2015;67(6):1001-1009.

PMID: 26134471

DOI: $10.1080 / 01635581.2015 .1053496$

32. Truan JS, Chen J, Thompson LU. Flaxseed oil reduces the growth of human breast tumors (MCF-7) at high levels of circulating estrogen. Mol Nutr Food Res. 2010;54(10):1414-1421.
PMID: 20425756

DOI: $10.1002 / \mathrm{mnfr} .200900521$

33. Wiggins AKA, Mason JK, Thompson LU. Growth and gene expression differ over time in alpha-Linolenic acid treated breast cancer cells. Exp Cell Res. 2015;333:147154.

PMID: 25743093.

DOI: 10.1016/j.yexcr.2015.02.020.

34. Altenburg JD, Bieberich AA, Terry C, Harvey KA, VanHorn JF, Xu Z, Davisson VJ, Siddiqui RA. A synergistic antiproliferation effect of curcumin and docosahexaenoic acid in SK-BR-3 breast cancer cells: unique signaling not explained by the effects of either compound alone. BMC cancer. 2011;11(1):1.

PMCID: PMC3111403

DOI: 10.1186/1471-2407-11-149

35. Kalyanaraman B, Darley-Usmar V, Davies $\mathrm{K}$, et al. Measuring reactive oxygen and nitrogen species with fluorescent probes: Challenges and limitations. Free Radic Biol Med. 2012;52(1):1-6.

PMCID: PMC3911769

DOI: 10.1016/j.freeradbiomed.2011.09.030

(c) 2017 Aldhirgham et al.; This is an Open Access article distributed under the terms of the Creative Commons Attribution License (http://creativecommons.org/licenses/by/4.0), which permits unrestricted use, distribution, and reproduction in any medium, provided the original work is properly cited.

Peer-review history:

The peer review history for this paper can be accessed here: http://sciencedomain.org/review-history/17312 